\title{
Micropropagation of rootstocks of stone fruit cultures in vitro
}

\author{
Marina Vinter*, Svyatoslav Fedorovitch, Marina Karpushina, and Sergey Gridnev \\ Federal State Budget Scientific Institution «North Caucasian Federal Scientific Center of \\ Horticulture, Viticulture, Wine-making», 39 str. 40 Let Pobedy, Krasnodar, 350901, Russia
}

\begin{abstract}
The usage of the method of clonal micropropagation of plants is currently the most promising for obtaining virus-free plant material, including clonal rootstocks of stone fruit cultures. The introduction of clonal rootstocks of stone fruit cultures PK SK1, PK SK 2, AI 1 into invitro culture is best doneduring the active shoot growth period - in the second decadeof May. During this period, the highest level of explants regeneration was noted: in the rootstock PK SK $1-94,6 \%$, in the rootstock AI 1 - 78.2\%, in PK SK 2 - 80.4\%, in Gisela 5 (control) - 85,7\%. From the third decade of May, the survival rate of explants begins to decline. At the stage of multiplication on the Murashige-Skoog medium, with the addition of 6-BAP $1 \mathrm{mg} / \mathrm{L}$, the average multiplication factor of clonal rootstocks to the fourth passage was 1: 12 for PK SK1, for Gisela 5 and for AI 1- 1: 8.
\end{abstract}

\section{Introduction}

The rootstock plays a significant role in the formation of crop yields, it determines the time when the trees enter into fruiting, the general state of plants, and the duration of the garden [1]. In the modern conditions of intensification of fruit production, the need for dwarf rootstocks is increasing, which will provide restrained plant growth, a compact crown of trees, thereby facilitating maintenance and harvesting [2]. The positive aspects of modern clonal rootstocks, in addition to the high productivity of grafted varieties, are genetic homogeneity, resistance to changing abiotic and biotic stressors of the environment, good fixation in the soil and almost complete absence of root growth, compatibility with varieties, easy propagation by vegetative methods [3].

Currenttechnology of growing fruit crops is impossible without the use of a healthy planting material. Clonal micropropagation is a widely used method for the commercial production of fruit stocks [4-6]. When growing stone fruit crops on clonal rootstocks, it is easier to obtain virus-free planting material [2].

The advantages of the method of clonal micropropagation of plants are rather short terms of reproduction and high yield of marketable products [7].

However, the process of micropropagation itself consists of several stages, at each of which a number of difficulties may arise associated with the specific genotypic response of

\footnotetext{
*Corresponding author:marina_winter@mail.ru
} 
the plant to in vitro conditions (composition of the nutrient medium, plant growth regulators, physical conditions of cultivation, etc.) [8-9].

So, at the stage of introduction into in vitro culture, it is necessary to take into account the seasonality of growth processes taking place in plants. The ability of explants to regenerate depends on the initiation period. As a rule, explants selected during the period of active growth of shoots have the highest regenerative activity [10].

One of the factors for the success of reproduction is the composition of the nutrient medium. Most often, for clonal micropropagation of rootstocks of small-seed cultures (cherries, sweet cherries), modified media of Murashige and Skoog (MS), DKW, WPM, Schenk and Hildebrandt ( $\mathrm{SH})$ are used, with various variations of hormonal substances, vitamins, macronutrients, sucrose [10-15] , for large-seed crops (plum, cherry-plum, apricot, peach) - the environment of Murashige and Skoog (MS), DKW, Quorina-Lepuavra (QL) [4, 16-19]. Optimizing the composition of the environment for a specific plant genotype is of particular importance, because even within the same species, plants may exhibit different reactions. The search for the optimal amounts of growth substances necessary for effective plant reproduction is very important, as an excess of hormones such as 6-BAP (6-benzylaminopurine), TDZ (thidiazuron) often leads to vitrification and chlorosis in regenerant plants, and in addition can inhibit growth processes in plants [15].

Therefore, in spite of the fact that the methods of breeding varieties and rootstocks of stone fruit crops have already been quite well developed, for each variety and rootstock, an individual study of all stages is necessary, taking into account the peculiarities of the genotype of explants.

The aim of our work was to search for the optimal composition of the nutrient medium and the timing of the selection of explants for introduction into in vitro conditions for the cultivation of explants of clonal rootstocks of large-seed PC SK 1, PC SK 2 and small-seed cultures - AI 1.

\section{Materials and methods}

The studies were carried out in the laboratory of virology of the Federal State Budgetary Scientific Institution (FSBSI) "North Caucasian Federal Scientific Center for Horticulture, Viticulture, Winemaking" (NCFSCHVW) and the laboratory of biotechnology of LLC OPKh"n. by K.A. Timiryazeva ". The objects of the study were clonal stocks for large-seed cultures PK SK 1 (PCG 25/1), PK SK 2 (PCG 13/1), stock for small-seed cultures AI 1 and Gisela 5 (control).

The rootstocks PK SK 1 and PK SK 2 are the result of joint selection of the FSBSI NCFSCHVW and the Stavropol Experimental Breeding Station, were distinguished for a number of valuable traits, patented and entered into the State Register of Breeding Achievements of Russia [2]. Rootstock AI 1 is under cultivation.

As initial explants, we used explants from buds awakened in laboratory conditions and actively growing tops of shoots from adult plants grown ex situ in the Experimental Nursery«n. by K.A. Timiryazeva», Ust-Labinsk region.

Surface sterilization was carried out according to the scheme: preliminary washing of plant material under running water for 1 hour, treatment with $70 \%$ alcohol (5 seconds), washing three times with autoclaved distilled water. The main treatment was carried out with a $0.5 \%$ solution of sodium salt of dichloroisocyanuric acid (in the composition of disinfecting tablets "OKA-TAB"), followed by five-fold washing with autoclaved distilled water. For the introduction, the medium was used according to the prescription of Murashige-Skoog with the addition of vitamins: B1 - $0.1 \mathrm{mg} / \mathrm{l}, \mathrm{B} 6, \mathrm{PP}-0.5 \mathrm{mg} / \mathrm{l}, \mathrm{C}-1$ 
$\mathrm{mg} / \mathrm{l}$, 6-BAP - $0.2 \mathrm{mg} / \mathrm{l}$, at the stage of multiplication of 6-BAP in an amount of $1 \mathrm{mg} / \mathrm{l}$, sucrose $(30 \mathrm{~g} / \mathrm{l})$, agar-agar $(6.5 \mathrm{~g} / \mathrm{l}), \mathrm{pH} 5.8$ were used as a carbon source.

The explants were cultivated at a temperature of $24-26^{\circ} \mathrm{C}$, a photoperiod of $16 / 8$ hours with an intensity of 3500 lux. Subculture was performed every 4 decades.

\section{Results and discussion}

For successful clonal micropropagation of fruit crops on artificial nutrient media, the timing of the introduction of explants into in vitro culture is of great importance.

In order to determine the optimal timing for the introduction of clonal rootstocks PK SK 1, PK SK 2, AI -1 and Gizela 5 (control) into in vitro culture, explants were selected in several periods.

Based on the fact that the peak of shoot growth in the southern zone of horticulture falls on May, and with the onset of high temperatures and lack of precipitation, the activity of shoot growth begins to decrease (June-July), the introduction into the culture was carried out in April and May. 10 days after the introduction of the explants on the nutrient medium, their survival rate was recorded (Fig. 1).

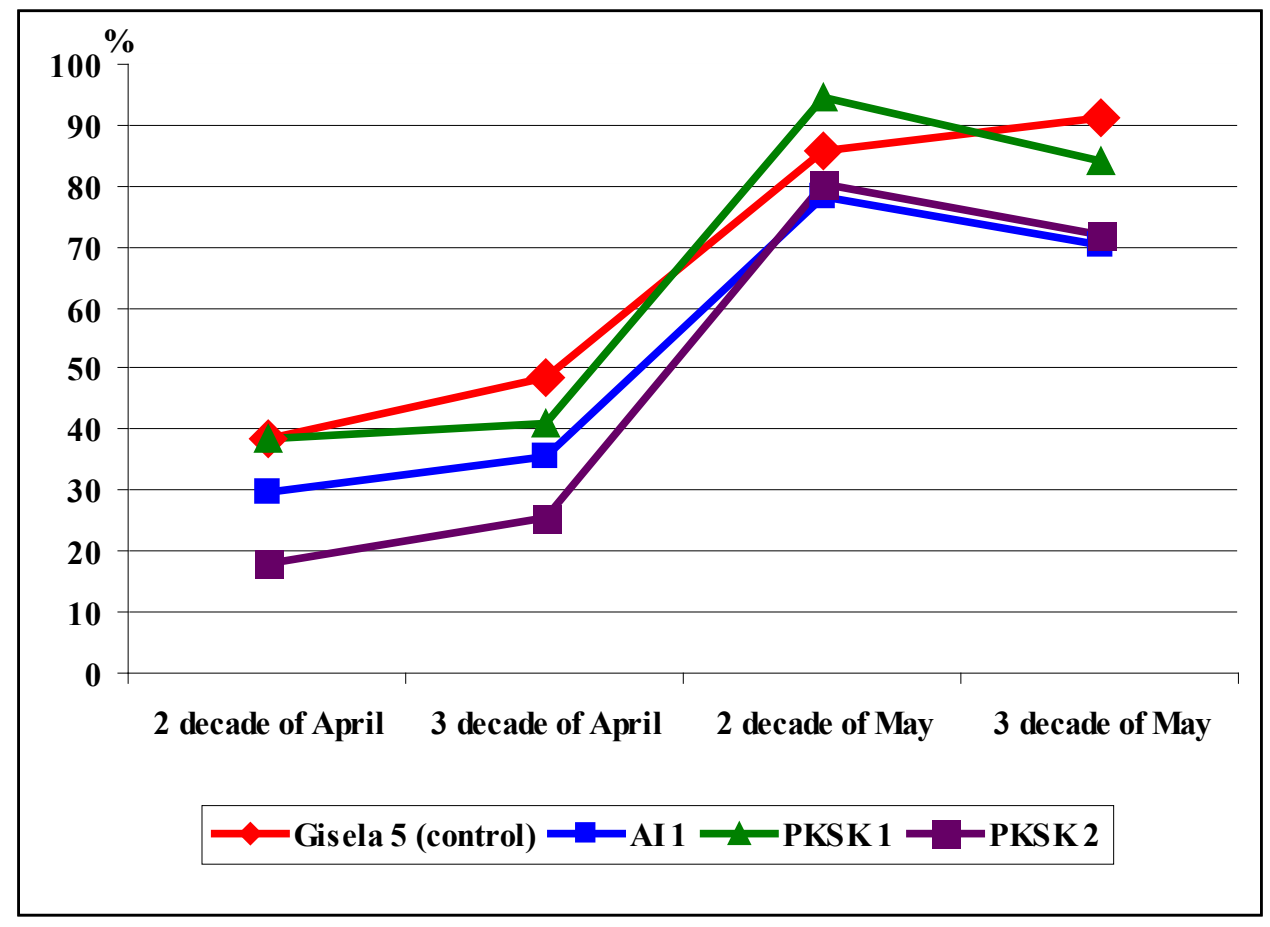

Fig. 1. The survival rate of explants of stone fruit rootstocks at the stage of introduction into an in vitro culture at different times

The analysis of the results of the obtained data on the survival rate shows that during the initiation of explants in the second decade of April, when explants have been selected from awakening buds in laboratory conditions, the survival rate of explants ranges from $18 \%$ in PK SK 2 to $38.6 \%$ in PK SK 1, in the third decade of April, the number of regenerated explants increases to $25.7 \%$ in PC SK 2, 35.4\% in AI 1, 40.8\% in PC SK 1, and $48.6 \%$ in Gisela 5 . The highest level of meristem regeneration was noted in the second decade May, when explants were scavenging from actively growing shoots. During this 
period, the survival rate of the rootstock PK SK 1 is $94.6 \%$, in the rootstock AI $1-78.2 \%$, in PK SK 2 - 80.4\%, in Gisela 5 - 85.7\%.

From the third decade of May, the regeneration of explants begins to decrease, in AI 1 by $8 \%$ and is $70.2 \%$, in SK 1 by $10.3 \%$ and is $84.3 \%$, in SK 2 by $8.4 \%$ and is $72 \%$. The survival rate of Gisela 5 explants remains at a high level and amounts to $91.1 \%$.

Thus, initiation into in vitro culture of rootstocks of stone fruit cultures AI 1, PK SK 1, PK SK 2, Gisela 5 is most effective during the period of active shoot growth, in the second - third decade of May.

At the stage of clonal micropropagation, the explants were transplanted onto the Murashige and Skoog medium containing vitamins B1 - $0.1 \mathrm{mg} / \mathrm{L}, \mathrm{B} 6, \mathrm{PP}-0.5 \mathrm{mg} / \mathrm{L}, \mathrm{C}-1$ $\mathrm{mg} / \mathrm{L}$, 6-BAP - $1 \mathrm{mg} / \mathrm{L}$, sucrose - $30 \mathrm{~g} / \mathrm{L}$. The efficiency of reproduction was assessed by the coefficient of reproduction (Fig. 2, 3), the height of the shoots, the state of the shoots (chlorosis, vitrification).

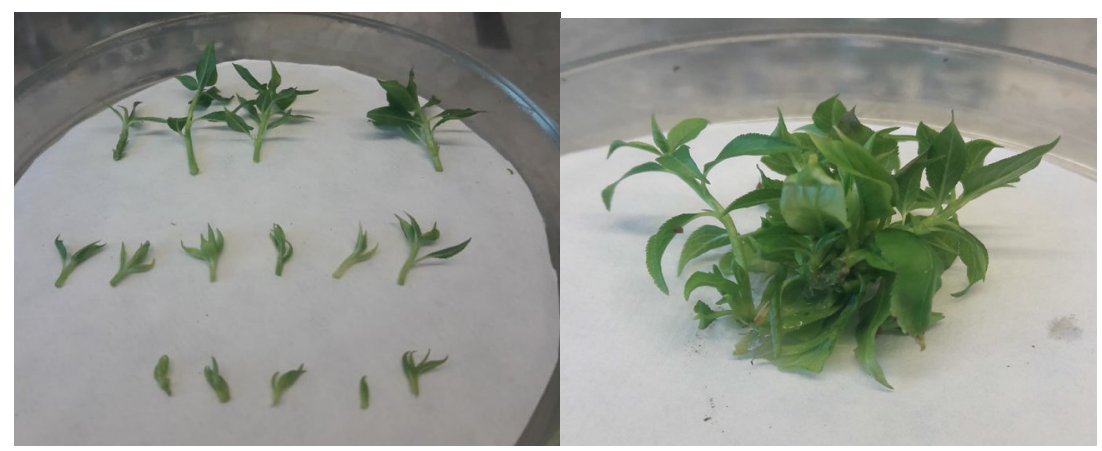

A

B

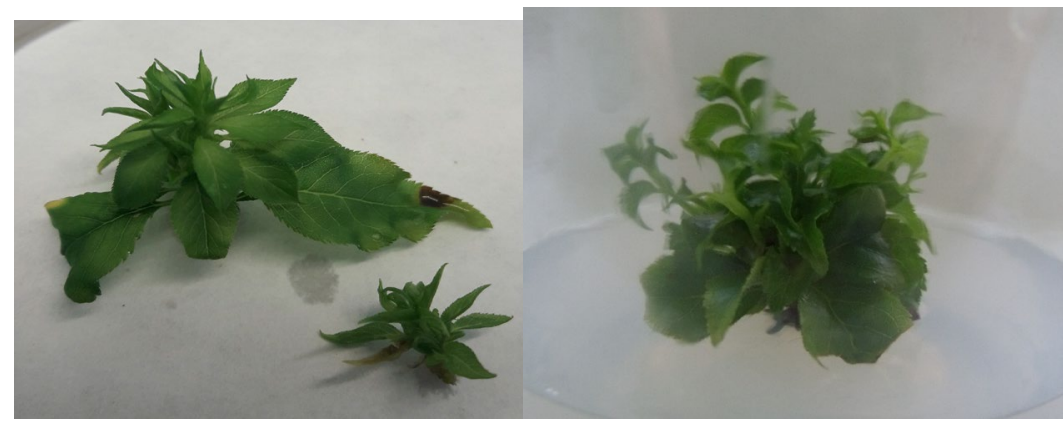

C

D

Fig. 2. Microshoots of clonal rootstocks. A, B - PK SK 1, C - AI 1, D - Gisela 5 


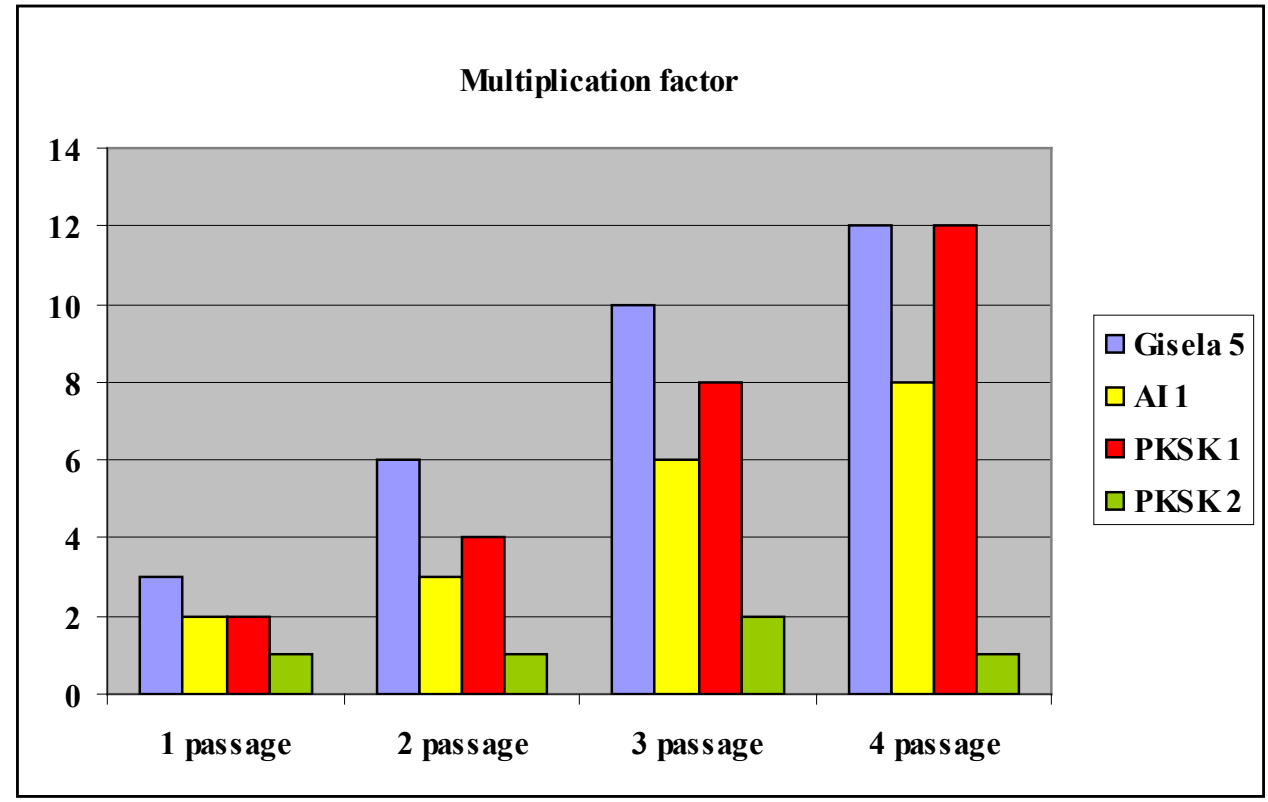

Fig. 3. Multiplication factor of clonal rootstocks of stone fruit crops

As can be seen from the data presented, the intensity of reproduction of clonal rootstocks increases with each passage, but the ability to reproduce in the varieties was not the same. The most active reproduction on MS medium with the addition of 6-BAP - $1 \mathrm{mg}$ / L was noted in the stock Gisela 5 (control) and PK SK 1. By passage 4, on average, for the rootstock PK SK 1 the multiplication factor was 1:12, as for the rootstock Gisela 5, for rootstock AI 1 this indicator was within 1: 8, in the PK SK 2 rootstock there was practically no multiplication of shoots. The presence of vitrified shoots was not observed. Microshoots PK SK 2 were distinguished by a pale green color of leaves.

Thus, we came to the conclusion that for the clonal rootstock PK SK 2 at the stage of proliferation, it is necessary to carry out an individual selection of the medium, since the medium used was not suitable for the propagation of this rootstock.

\section{Conclusion}

The initiation of clonal rootstocks into in vitro culture during the period of active shoot growth allows for a higher survival rate of explants. With the introduction of explants into an in vitro culture in the second decade of May, the survival rate of the rootstock SK 1 is 94.6\%, for the rootstock AI $1-78.2 \%$, for the PK SK $2-80.4 \%$, Gisela $5-85.7 \%$.

The use of the Murashige-Skuga nutrient medium with the addition of 6-BAP in an amount of $1 \mathrm{mg} / 1$ during micropropagation of clonal rootstocks of stone fruit crops allows to obtain an average multiplication factor for PK SK 1 and Gisela 5 rootstocks - 1:12, for AI 1 - 1: 8 .

\section{References}

1. A. Kuznetsova, F. Drigina, A. Fedorenko, M. Maslova, Fruit growing and viticulture of South Russia, 64(4), 128-142 (2020).http://doi.org/10.30679/2219-5335-2020-4-64- 
$128-142$

2. L. Orlova, S. Scheglov, A. Kuznetsova, Fruit growing and viticulture of South Russia, 58(4), 46-57 (2019).http://doi.org/10.30679/2219-5335-2019-4-58-46-57

3. A. Tsafouros, P. A. Roussos, Not Bot HortiAgrobo, 47(1), 152-161 (2019).https://www.doi.org/10.15835/nbha47111276

4. E. Kassaye, B.D. Bekele, Biotechnology International, 8(4), 137-148 (2015).http://www.bti.org.in/wp-content/uploads/2016/08/BTI-8.4.4.pdf

5. S. Godoy, E. Tapia, P. Seit, D. Andrade, E. Sánchez, P. Andrade, A.M. Almeida, H. Prieto, In Vitro Cell.Dev.Biol.-Plant, 53, 494-504 (2017).https://doi.org/10.1007/s11627-017-9856-z

6. A. Stanisavljević, D. Bošnjak, I. Štolfa, R. Vuković, T. Kujundžić, M. Drenjančević, Poljoprivreda, 23(2), 31-37, (2017).https://doi.org/10.18047/poljo.23.2.5

7. B. Hosseinpour, N. Bouzari, Z. Didar, M. Masoumian, S.A. Ghaemmaghami, A. Ebrahimi, S.M. Mirabbasi, A. Farvardin, IJGPB, 4 (2), 28-36, (2015).http://ijgpb.journals.ikiu.ac.ir/article_880.html

8. M. Fallahpour, S.M. Miri, N. Bouzari, J Hortic Res, V. 23(1), 57-64, (2015). http://doi.org/10.2478/johr-2015-0008

9. D. Dorić, V. Ognjanov, G. Barać, M. Ljubojević, A. Pranjić, K. Dugalić, S. Ercişli, Turk J Biol, 39, 575-581 (2015).https://doi.org/10.3906/biy-1412-85

10. D. Dorić, V. Ognjanov, M. Ljubojević, G. Barać, J, Dulić, A, Pranjić, K. Dugalić, Not Bot HortiAgrobo, 42(2), 488-494 (2014).https://doi.org/10.15835/nbha4229671

11. V. Sarropoulou, K. Dimassi-Theriou, I. Therios. Turk J Agric For, 37, 688-698 (2013).https://doi.org/10.3906/tar-1212-81

12. Ph. Druart, Micropropagation of Prunus Species Relevant to Cherry Fruit Production, In: M. Lambardi, E. Ozudogru, S. Jain (eds) Protocols for Micropropagation of Selected Economically-Important Horticultural Plants, Methods in Molecular Biology (Methods and Protocols), 994, 119-136 (2013).https://doi.org/10.1007/978-1-62703074-8 9

13. D. Bošnjaković, V. Ognjanov, G. Barać, M. Ljubojević, A. Pranjić, K. Dugalić, Journal of Pomology, 47, 121-128 (2013). https://www.researchgate.net/publication/ 269107920 MICROPROPAGATION OF LOW VIGOROUS ROOTSTOCKS SEL ECTIONS_FOR_SWEET_AND_SOŪR_C̄HERRY

14. S.M. Khamurzaev, I.M. Bamatov, E.M. Butsaeva, S.V. Sibiryatkin, Journal of Experimental Biology and Agricultural Sciences, 6(3), 623-627 (2018). http://dx.doi.org/10.18006/2018.6(3).623.627

15. M. Mahdavian, N. Bouzari, H. Abdollahi, Biharean Biologist, 5(2), 86-90 (2011).http://biozoojournals.ro/bihbiol/cont/v5n2/bb.111112.Mahdavian.pdf

16. M.I. Salih,, I.A. Al Shmarey, F.M.K. Al Dabagh, IOSR-JAVS, 9(7), 50-53 (2016).http://doi.org/10.9790/2380-0907025053

17. S. Amiri, S. Ashtari, A.H. Babaiy, S.A. Nazari, E. Khodadadi, E. Khodadadi, M. Sabzi, Ann Biol Res, 4(3), 149-151 (2013).https://www.researchgate.net/publication /235989226_Control_of_contamination_during_micropropagation_process_of_Rootsto cks_Mariana_Prunus_mariana

18. M. Pakyürek, - S. Hepaksoy, EJONS Journal, 8, 146-159, (2020).https://pdfs.semanticscholar.org/e826/823995ef7e39e0f76b633e5219bd9663792 5.pdf?.ga=2.109193989.1605528451.1595838082-1484798313.1595244390

19. O. Ostadsharif, G. Garoosi, R. Haddad, E. Nezami, AgricBiotechnol, 13(1), 9-21 (2014).http://www.ikiu.ac.ir/public-files/profiles/items/090ad_1435487423.pdf 